Revta brasil. Bot., São Paulo, V.23, n.2, p.169-176, jun. 2000

\title{
Potencial plástico de Cabralea canjerana subsp. polytricha (Adr. Juss.) Penn. (Meliaceae) e seu papel na formação de ecótipos em áreas de cerrado e vereda, Uberlândia, MG $^{1}$
}

\author{
ADRIANA PAULA FUZETO² e CECÍLIA LOMÔNACO ${ }^{3,4}$
}

(recebido em 7 de abril de 1999; aceito em 14 de janeiro de 2000)

\begin{abstract}
Plastic potential of Cabralea canjerana subsp. polytricha (Adr. Juss.) Penn. (Meliaceae) and its role on the ecotype formation in savanna and palm swamp areas, Uberlândia, MG). The ecotype formation of Cabralea canjerana subsp. polytricha in areas of savanna and palm swamp in an ecological reserve in Uberlândia, MG, was studied, using a quantitative genetic model to measure phenotypic plasticity. Ecotypes were characterised by the height of the individuals, weight of fruits and seeds, number of viable seeds per fruit and synchronization of the flowering period. There is great genetic variability in important fitness characters of the subspecies. The genotypes respond phenotypically to the environmental heterogeneity produced by the savanna/palm swamp gradient in two of the three measured characters. The plastic responses were distinct among genotypes in both direction and intensity. Asynchrony of the flowering period and the action of seed dispersers may contribute to increase the divergences of the ecotypes in the study area.
\end{abstract}

RESUMO - (Potencial plástico de Cabralea canjerana subsp. polytricha (Adr. Juss.) Penn. (Meliaceae) e seu papel na formação de ecótipos em áreas de cerrado e vereda, Uberlândia, MG). A formação de ecótipos em Cabralea canjerana subsp. polytricha foi estudada em áreas de cerrado e vereda de uma reserva ecológica no município de Uberlândia, MG, utilizando modelos de genética quantitativa para medida de plasticidade fenotípica. Os ecótipos foram caracterizados quanto à altura dos indivíduos, peso de frutos e sementes, número de sementes viáveis por fruto e sincronização no período de floração. Existe grande variabilidade genética para caracteres importantes na determinação do valor adaptativo da subspécie. Os genótipos respondem fenotipicamente à heterogeneidade ambiental, provocada pelo gradiente cerrado/vereda, em dois dos três caracteres observados. As respostas plásticas foram distintas entre os genótipos, quanto à direção e intensidade. Assincronia temporal de floração e o modo de ação de dispersores de sementes podem contribuir para a evolução da divergência entre ecótipos na área estudada.

Key words - Cabralea canjerana, ecotypes, phenotypic plasticity, quantitative genetics

\section{Introdução}

Variações fenotípicas podem ser decorrentes tanto das propriedades genéticas da população, quanto da influência do ambiente na expressão de seus genótipos. O efeito fenotípico provocado pela interação entre o ambiente e o genótipo é dito plasticidade fenotípica (Falconer 1989). Plasticidade fenotípica significa, portanto, qualquer tipo de variação fenotípica induzida pelo ambiente, sem que mudanças genotípicas sejam necessárias (Bradshaw 1965, Stearns 1989, Scheiner 1993). Uma vez que a seleção natural age sobre diferenças no fenótipo, a plasticidade fenotípica atua como um importante mecanismo gerador de variabilidade (Via 1990, Thompson 1991).

1. Parte do trabalho de monografia de bacharelado de A.P. Fuzeto.

2. Bolsista FAPEMIG.

3. Departamento de Biociências, Universidade Federal de Uberlândia, Caixa Postal 593, 38400-902 Uberlândia, MG, Brasil.

4. Autor para correspondência: lomonaco@ufu.br
Tanto animais quanto plantas podem apresentar respostas plásticas (Bradshaw 1965). Em plantas, a plasticidade fenotípica pode ser expressa no crescimento em altura, na anatomia e morfologia das estruturas vegetativas e reprodutivas, na alocação absoluta e relativa de biomassa, na taxa fotossintética e fenologia (Sultan 1987).

A plasticidade pode ser considerada como o mecanismo de adaptação mais importante para espécies vegetais em ambientes heterogêneos, uma vez que plantas são destituídas dos complexos mecanismos de movimentação e de comportamento peculiares dos animais (Bradshaw 1965). A plasticidade, no entanto, nem sempre é adaptativa, e somente o é se representa um mecanismo pelo qual o valor adaptativo relativo é mantido, em decorrência de variação ambiental (Thompson 1991, Scheiner 1993, Dudley \& Schmitt 1996, Pigliucci \& Schlichting 1996).

Se há grande potencial plástico em uma população que ocupa um ambiente heterogêneo, pode haver a formação de ecótipos por seleção disruptiva (Via et al. 1995). Segundo Sultan (1987), ecótipo pode ser definido pelos padrões de respostas morfológicas e fenológicas que contrastam entre ambientes distintos. Uma vez formados, os ecótipos 
podem evoluir, aumentando suas divergências, num processo que culminaria com o evento da especiação (Mackenzie \& Guldemond 1994). A especiação simpátrica é definida por Mayr (1982) como sendo a formação de uma nova espécie por meio de mecanismos de isolamento dentro das áreas de dispersão de um deme, por seleção disruptiva. Somente recentemente, com o surgimento de novas metodologias de análise quantitativa, a formação de ecótipos e a especiação simpátrica têm sido investigadas em populações de plantas (Lortie \& Aarssen 1996, Sultan 1996, Black \& Anderson 1997, Pigliucci et al. 1997).

Neste contexto, os objetivos deste trabalho foram verificar, com uso de modelos de genética quantitativa, o potencial plástico de Cabralea canjerana subsp. polytricha e seu papel na formação de ecótipos em uma reserva que abrange áreas de cerrado e vereda.

\section{Material e métodos}

Área de estudo - As coletas foram efetuadas em áreas preservadas da Reserva Ecológica do Clube Caça e Pesca Itororó de Uberlândia, MG (18 $55^{\prime} 23^{\prime \prime}$ S e $\left.48^{\circ} 17^{\prime} 19^{\prime \prime} \mathrm{W}\right)$, situada a oeste do município, distando $10 \mathrm{~km}$ do centro da cidade. A amostragem concentrou-se em uma área de $10 \mathrm{ha}$, onde se observa um gradiente cerrado/vereda. O clima dessa região é caracterizado por duas estações bem definidas: seca e úmida, podendo apresentar tanto temperaturas acima de $35^{\circ} \mathrm{C}$ como geadas esporádicas no inverno. A precipitação anual e as médias diárias de temperatura oscilam em torno de $1550 \mathrm{~mm}$ e $22^{\circ} \mathrm{C}$, respectivamente (Nimer \& Brandão 1989).

A planta - Cabralea canjerana (Vellozo) Martius é uma Meliaceae de porte arbóreo-arbustivo (Barreiros \& Souza 1986), que ocorre na região neotropical desde a Costa Rica até o nordeste da Argentina. Popularmente, é conhecida por "canjerana do brejo", "gergelin", "canjerano", "canharana", "cambarano" e "rebenta cavalo" (Pennington et al. 1981). Está representada no Brasil por três subspécies, que divergem ecologicamente quanto aos nichos que ocupam, pois sua distribuição responde à tipologia de solos, formas de relevo, clima e proximidade de redes hidrográficas (Pennington et al. 1981, Barreiros \& Souza 1986). C. canjerana subsp. polytricha (Adr. Jussieu) Penn. parece estar restrita aos estados de Minas Gerais e Goiás (Pennington et al. 1981, Barreiros \& Souza 1986). A subspécie é dióica (A. P. Fuzeto et al., dados não publicados), apresentando ovário com quatro ou cinco lóculos, cada lóculo com dois óvulos superpostos. Os frutos são vermelhos, com cápsula loculicida e pericarpo carnoso, sendo tardiamente deiscentes (Pennington et al. 1981). Suas sementes são elipsóides e totalmente cobertas por arilo (Barroso 1984, Barreiros \& Souza 1986). Segundo Rizzini (1977), a dispersão de sementes corresponde ao período de chuvas, que favorece a germinação (in natura) destas, que não suportam mais que poucos dias em solo seco.
Caracterização dos ecótipos - Indivíduos adultos de C. canjerana subsp. polytricha foram identificados e marcados em suas áreas de ocorrência. Foram obtidas medidas de altura de 46 plantas de cerrado e 35 de vereda. Dentre estas, foram escolhidos aleatoriamente sete indivíduos pertencentes à área de cerrado e cinco pertencentes à área de vereda. De cada um destes indivíduos, 20 frutos foram coletados ao acaso e pesados. Destes, oito frutos tiveram suas sementes retiradas e contadas. As sementes viáveis (bem formadas morfologicamente) foram pesadas, pós a extração da camada arilóide. Uma estimativa indireta de densidade populacional foi feita avaliando a distância ao vizinho mais próximo. Nesta análise foram considerados 43 indivíduos na área de cerrado e 15 indivíduos na área de vereda. A verificação estatística das diferenças entre peso dos frutos e de sementes, número de sementes viáveis por fruto, distância e altura de indivíduos entre as áreas, foi feita por teste $\mathrm{t}$ (Zar 1982).

As sementes morfologicamente viáveis $(\mathrm{n}=766)$ foram postas para germinar (em lotes por fruto) em 96 recipientes plásticos, contendo algodão embebido em água, umedecidos diariamente. Após 10 dias, as sementes que germinaram com sucesso $(n=507)$ foram dispostas em duas bandejas de isopor para germinação, cada uma contendo amostras de solo coletadas de cada uma das áreas. As sementes recém germinadas foram distribuídas nas subdivisões (células) das bandejas, de tal modo que, aquelas provenientes de um mesmo fruto foram colocadas simultaneamente em ambos os tipos de solo. Este procedimento foi efetuado em laboratório, onde as sementes permaneceram à temperatura ambiente (cerca de $27^{\circ} \mathrm{C}$ ). Decorridos 30 dias, as plântulas formadas $(n=273)$ foram transplantadas para sacos plásticos, seguindo-se o mesmo critério de representatividade nos tipos de solo. Nesta etapa, as plântulas foram deixadas em estufa (temperatura em torno de $30^{\circ} \mathrm{C}$ ), com irrigação em intervalos de dois dias.

A proporção de sementes, segundo sua viabilidade morfológica, fisiológica e sobrevivência até a fase de plântula, foi analisada comparativamente entre as áreas, por meio de tabela de contingência em quatro levantamentos que consideraram: 1) número de sementes morfologicamente viáveis, após abertura manual dos frutos; 2) número de sementes que germinaram com sucesso, decorridos 10 dias; 3) número de plântulas que se desenvolveram com sucesso até o transplante para as bandejas de germinação (30 dias após germinação) e 4) número de plântulas sobreviventes até o transplante para os sacos plásticos (30 dias após transplante para bandejas). A percentagem de sobrevivência ao final do experimento foi calculada dividindo-se o número de sobreviventes observados no quarto levantamento pelo número máximo de sementes que poderiam ter sido obtidas em cada área, considerando o número de frutos coletados (560 sementes para área de cerrado e 400 sementes para área de vereda).

Plasticidade fenotípica - Medidas da altura da parte aérea das plântulas, comprimento e número de folhas foram tomadas 30 dias após o plantio nas bandejas de germinação (censo 1). O mesmo procedimento foi realizado 30 dias após transplante para os sacos plásticos (censo 2). A variabilidade fenotípica total apresentada pela população, para cada caráter analisado (altura da parte aérea, comprimento e número de folhas das plântulas), foi decomposta nas três fontes geradoras de variabilidade: o fator genético, a influência ambiental e a interação entre ambos. A decomposição da variância total encontrada entre seus componentes permite que a importância relativa dos vários determinantes do fenótipo seja 
estimada. Deste modo, a variação fenotípica total equivale à soma de seus componentes, sendo $\mathrm{Vf}=\mathrm{Vg}+\mathrm{Va}+\mathrm{Vge}$, onde Vf é a variação fenotípica total da população amostrada, Vg é a variação atribuída à diferença genética entre as plântulas, Va é a variação atribuída aos fatores ambientais que diferiam entre os solos das áreas amostradas e Vge é a variação atribuída à interação entre os componentes genético e ambiental (Falconer 1989). Segundo Via \& Lande (1985), a quantidade de variação atribuída a cada componente pode ser avaliada por meio dos valores das médias dos quadrados (MQ), que correspondem às variâncias propriamente ditas atribuídas a cada componente, obtidas da análise de variância para dois fatores. Deste modo, os fatores considerados nas três análises e nos dois censos foram: fruto (com níveis variando de 32 a 34), que corresponde ao componente genético de variação e área (com dois níveis: cerrado e vereda), que corresponde ao componente ambiental de variação. A variabilidade nas respostas plásticas dos genótipos analisados foi estimada, para cada caráter, pela interação entre os fatores obtidos na ANOVA para dois fatores (Via \& Lande 1985, Scheiner 1993). Uma vez que as análises de variância informam apenas a quantidade de variação atribuída a cada um de seus componentes, foram construídas para cada caráter analisado, no segundo censo, normas de reação que representam graficamente a direção das respostas plásticas e a variabilidade entre os genótipos (frutos) quanto às suas respostas plásticas. A impossibilidade de caracterização das sementes provenientes de um mesmo fruto como sendo meio-irmãs ou irmãs completas não permitiu que a variabilidade genética total fosse decomposta, quanto à aditividade e dominância (Falconer 1989). Também foram efetuados testes de correlação simples de Pearson para verificação de ocorrência de "trade-offs" ou correlações genéticas significativas entre a expressão de um mesmo caráter em dois ambientes (Via \& Lande 1985, Falconer 1989), como forma de avaliar a variabilidade para a plasticidade em uma população natural (Pigliucci \& Schlichting 1996).

A ocorrência de mecanismos de isolamento, mantenedores ou amplificadores da divergência entre os ecótipos, foi avaliada por meio de três experimentos que verificaram: 1) diferenças relativas no sucesso de frutificação e desenvolvimento de frutos produzidos por cruzamentos entre e dentro de ecótipos; 2) ocorrência de assincronia na floração entre as áreas e 3) favorecimento ao estabelecimento de plântulas nas suas áreas de origem, pela ação de dispersores de sementes.

Para verificar se havia diferenças entre o sucesso de frutificação decorrente da polinização cruzada entre os ecótipos, tratamentos florais foram realizados em plantas no campo, no período de setembro a outubro de 1997. Flores foram polinizadas manualmente em quatro tipos de cruzamentos: cerrado vs. cerrado $(\mathrm{n}=112)$, cerrado vs. vereda $(\mathrm{n}=148)$, vereda vs. vereda $(n=136)$ e vereda vs. cerrado $(n=157)$. O desenvolvimento dos frutos provenientes destes tratamentos foram acompanhados em duas visitas quinzenais ao campo (visita 1 e visita 2), em que o número de frutos formados e sua largura foram estimados. Diferenças estatísticas no sucesso de frutificação (número de frutos formados) entre os tratamentos foram verificadas por tabela de contingência. $O$ desenvolvimento diferencial, estimado por meio de medidas no diâmetro dos frutos produzidos nos diferentes tratamentos, foi avaliado por meio de análise de variância (Zar 1982). O número de medidas de diâmetro para cada visita e cada tratamento variou de 9 a $30(18,5 \pm 6,4)$.
Para verificação de ocorrência de assincronia na floração entre as áreas de coleta, os diferentes estádios do desenvolvimento floral foram caracterizados em seis fases: 0 - ausência de botões; I - botões totalmente imaturos de cor verde; II - botões imaturos, mas com a extremidade superior amarelada; III - botões amareloesverdeados; IV - botões de cor creme em pré-antese; V - flores abertas. O estádio de floração de 46 indivíduos do cerrado (27 pistilados e 19 estaminados) e de 35 indivíduos de vereda (17 pistilados e 18 estaminados) foi anotado e diferenças nas freqüências de ocorrência em cada fase e entre as áreas foram testadas por tabela de contingência (Zar 1982).

Para observar o modo de ação dos agentes dispersores de sementes, foram realizadas observações, num total de $20 \mathrm{~h}$, dos potenciais dispersores das sementes de $C$. canjerana subsp. polytricha, no período de 21 a 26 de setembro de 1998. As observações concentraram-se no intervalo compreendido entre 8:00 e 11:30 h, sendo realizadas a uma distância de aproximadamente dois metros da planta estudada. Foram escolhidos, como objetos de observação, indivíduos que possuíam frutos com deiscência completa e sementes expostas. As espécies de aves que pousavam sobre a planta eram fotografadas, e caracterizadas quanto à freqüência de visitação e comportamento de apreensão e ingestão de sementes. Como algumas sementes foram encontradas sob o dossel da planta mãe, após a visita de dispersores, a viabilidade fisiológica destas sementes foi verificada em teste de germinação. Neste teste, 43 sementes capturadas foram acondicionadas em recipientes com algodão embebido em água e observadas por 15 dias, para detecção de percentagem de germinação.

\section{Resultados}

Caracterização dos ecótipos - A análise estatística de dados relativos à altura dos indivíduos adultos de $C$. canjerana subsp. polytricha indica que os indivíduos pertencentes à área de cerrado apresentam maior porte em relação aos de vereda. O peso médio dos frutos dos indivíduos do cerrado também foi maior, quando comparado com o de vereda. Não houve diferenças significativas no peso das sementes e número de sementes viáveis por fruto entre as áreas de coleta. Maior densidade populacional foi observada na área de cerrado, onde a distância média entre indivíduos foi menor, em relação à de vereda (tabela 1).

A viabilidade morfológica, fisiológica e sobrevivência de sementes, desde a abertura dos frutos até o estágio de plântula, foi equivalente em ambas as áreas (23,5\% no cerrado e $23,7 \%$ na vereda), não diferindo estatisticamente nos quatro levantamentos efetuados $\left(\chi^{2}=0,56 ; \mathrm{p}<0,05\right)$.

Plasticidade fenotípica - No primeiro censo, as três variáveis analisadas diferiram significativamente entre os genótipos (frutos), indicando haver grande variabilidade genética ou seja, significativa atuação 
deste fator na variabilidade fenotípica observada ( $\mathrm{F}=3,1 ; \mathrm{p}<0,001$, para altura da parte aérea da plântula; $F=3,5 ; \mathrm{p}<0,001$, para comprimento de folhas e $F=3,1 ; p<0,001$, para número de folhas das plântulas). Diferenças quantitativas destes mesmos caracteres nas plântulas cultivadas nos diferentes tipos de solo (áreas) foram significativas apenas para a altura da parte aérea da plântula $(\mathrm{F}=3,8$; $\mathrm{p}=0,05)$, o que mostra haver plasticidade para este caráter, visto que respondem às diferenças ambientais. Não houve interação significativa entre os fatores $(\mathrm{F}=1,2 ; \mathrm{p}=0,27$, para altura da parte aérea da plântula; $\mathrm{F}=1,1 ; \mathrm{p}=0,33$, para comprimento de folhas e $F=0,8 ; p=0,72$, para número de folhas), indicando a ocorrência de pequena variabilidade entre os genótipos em suas respostas plásticas (tabela 2).

No segundo censo, as três variáveis diferiram significativamente entre os frutos ou genótipos $(\mathrm{F}=3,3 ; \mathrm{p}<0,001$, para altura da parte aérea da plântula; $\mathrm{F}=2,9 ; \mathrm{p}<0,001$, para comprimento de folhas e $\mathrm{F}=1,4 ; \mathrm{p}=0,08$, para número de folhas). Diferenças quantitativas destes mesmos caracteres, nas áreas de estudo, não foram verificadas estatisticamente (tabela 2), mas as normas de reação mostraram divergências na direção de variação para os caracteres analisados (figura 1). Houve significativa interação entre os fatores para os seguintes caracteres: altura da parte aérea da plântula $(F=1,5$; $\mathrm{p}=0,05)$ e comprimento das folhas $(\mathrm{F}=1,6$; $\mathrm{p}=0,04)$, indicando que cada genótipo responde aos fatores ambientais de modo distinto (tabela 2).

No censo 1, as correlações genéticas foram positivas e significativas para apenas dois dos três carac- teres analisados: comprimento de folhas $(\mathrm{r}=0,55$; $\mathrm{p}=0,01)$ e número de folhas $(\mathrm{r}=0,55 ; \mathrm{p}=0,01)$. No censo 2 , as correlações genéticas não foram significativas $(\mathrm{r}=0,47 ; \mathrm{p}=0,18$, para altura da parte aérea; $\mathrm{r}=0,39 ; \mathrm{p}=0,59$, para comprimento das folhas e $\mathrm{r}=0,20 ; \mathrm{p}=1,00$, para número de folhas). Não houve, portanto, confirmação quantitativa de ocorrência de "trade-offs" (correlações genéticas negativas), embora estes tenham sido detectados nas normas de reação (diferentes respostas plásticas entre genótipos).

Não houve diferenças estatísticas significativas entre os tratamentos no sucesso de frutificação $\left(\chi^{2}=5,448 ; \mathrm{p}<0,005\right)$. Entretanto, frutos maiores foram observados nos cruzamentos cerrado vs. cerrado e menores no tratamento vereda vs. vereda $(\mathrm{F}=14,75 ; \mathrm{p}<0,001$, na visita $1 ; \mathrm{F}=6,34$; $\mathrm{p}=0,001$, na visita 2 ). Frutos provenientes de cruzamentos entre os ecótipos (cerrado vs. vereda ou vereda vs. cerrado) apresentaram tamanhos intermediários (figura 2).

Não houve sincronia quanto aos estádios de floração entre as áreas $\left(\chi^{2}=12,176 ; \mathrm{p}<0,05\right)$, uma vez que os indivíduos de cerrado apresentam estádios de floração mais adiantados que os de vereda (figura 3).

Foram registradas seis espécies de pássaros visitando C. canjerana subsp. polytricha. Três destas espécies são da família Tyrannidae (Tyrannus savana Viellot, Elaenia flavogaster Thumberg e Pitangus sulphuratus L.), uma pertence à família Ramphastidae (Ramphastos toco P.L.S. Müller) e duas espécies não puderam ser identificadas. Somente E. flavogaster foi observada ingerindo as

Tabela 1. Caracterização e diferenciação dos ecótipos de Cabralea canjerana subsp. polytricha, nas áreas de estudo da Reserva Ecológica do Clube Caça e Pesca Itororó de Uberlândia, MG, 1997, quanto à altura dos indivíduos, peso dos frutos, peso das sementes, número de sementes morfologicamente viáveis por fruto e densidade (estimada indiretamente pela distância mínima entre indivíduos).

\begin{tabular}{|c|c|c|c|c|c|c|}
\hline \multirow[t]{2}{*}{ Componentes analisados } & \multicolumn{2}{|c|}{ Cerrado } & \multicolumn{2}{|c|}{ Vereda } & \multirow[t]{2}{*}{$\mathrm{t}$} & \multirow[t]{2}{*}{$\mathrm{p}$} \\
\hline & Média & $\pm(S)$ & Média & $\pm(S)$ & & \\
\hline Altura da planta $(\mathrm{m})$ & 1,80 & 0,48 & 1,20 & 0,63 & 4,75 & $<0,0001$ \\
\hline Peso dos frutos $(\mathrm{g})$ & 5,50 & 1,60 & 4,20 & 0,77 & 4,42 & $<0,0001$ \\
\hline Peso de sementes (g) & 0,09 & 0,03 & 0,10 & 0,04 & 1,81 & 0,07 \\
\hline Número de sementes viáveis & 8,20 & 1,74 & 7,70 & 1,68 & 1,46 & 0,16 \\
\hline Distância entre indivíduos (m) & 4,40 & 0,50 & 39,08 & 10,13 & 13,41 & $<0,0001$ \\
\hline
\end{tabular}

S: Desvio padrão. 
Tabela 2. ANOVA para dois fatores (frutos e áreas) de medidas de altura da parte aérea, comprimento e número de folhas por plântula de Cabralea canjerana subsp. polytricha, desenvolvidas em solos de cerrado e de vereda, da Reserva Ecológica do Clube Caça e Pesca Itororó de Uberlândia, MG, 1997 (censos 1 e 2).

\begin{tabular}{|c|c|c|c|c|c|c|c|}
\hline \multirow[t]{2}{*}{ Variável } & \multirow[t]{2}{*}{ Fonte } & \multicolumn{3}{|c|}{ Censo 1} & \multicolumn{3}{|c|}{ Censo 2} \\
\hline & & MQ & $\mathrm{F}$ & $\mathrm{p}$ & MQ & $\mathrm{F}$ & $\mathrm{p}$ \\
\hline \multirow[t]{4}{*}{ Altura da parte aérea da plântula } & fruto & 9,58 & 3,1 & $<0,001$ & 7,35 & 3,3 & $<0,001$ \\
\hline & área & 11,71 & 3,8 & 0,05 & 2,59 & 1,2 & 0,28 \\
\hline & fruto vs. área & 3,57 & 1,2 & 0,27 & 3,40 & 1,5 & 0,05 \\
\hline & erro & 3,08 & & & 2,20 & & \\
\hline \multirow[t]{4}{*}{ Comprimento das folhas } & fruto & 0,99 & 3,5 & $<0,001$ & 0,47 & 2,9 & $<0,001$ \\
\hline & área & 0,75 & 2,7 & 0,11 & 0,02 & 0,1 & 0,70 \\
\hline & fruto vs. área & 0,31 & 1,1 & 0,33 & 0,25 & 1,6 & 0,04 \\
\hline & erro & 0,28 & & & 0,16 & & \\
\hline \multirow[t]{4}{*}{ Número de folhas por plântula } & fruto & 11,96 & 3,1 & $<0,001$ & 3,87 & 1,4 & 0,08 \\
\hline & área & 2,43 & 0,6 & 0,43 & 0,54 & 0,2 & 0,65 \\
\hline & fruto vs. área & 3,28 & 0,8 & 0,72 & 3,33 & 1,2 & 0,20 \\
\hline & erro & 3,91 & & & 2,68 & & \\
\hline
\end{tabular}

MQ: Média dos quadrados.

sementes de Cabralea. Seu comportamento era caracterizado pelo canto prolongado, quando pousava sobre a planta, antes de começar a ingerir os diásporos. Todas as sementes de um único fruto eram ingeridas por esta espécie em aproximadamente $30 \mathrm{~min}$. Geralmente, algumas sementes com proporções maiores que o bico do indivíduo eram lançadas ao chão após serem captadas. T. savana, $P$. sulphuratus $e$ duas espécies não identificadas somente foram observadas pulando de um galho a outro, e, às vezes, bicando alguns frutos fechados. $R$. toco bicava os frutos lançando-os ao chão sem, contudo, ingerí-los. Os frutos semi-abertos com sementes intactas e algumas sementes espalhadas entre a serapilheira eram freqüentemente visitados e transportados por formigas. Testes indicaram $83,72 \%$ de sucesso de germinação neste material.

\section{Discussão}

Existe grande variabilidade genética em Cabralea canjerana subsp. polytricha na área estudada, para caracteres importantes na determinação de seu valor adaptativo. Além disto, os diferentes genótipos respondem fenotipicamente à heteroge- neidade ambiental, provocada pelo gradiente cerrado/vereda, o que assegura seu desenvolvimento em condições heterogêneas. Diferentes intensidades e direções nas respostas também indicam haver grande variabilidade genética para plasticidade em pelo menos dois dos três caracteres analisados (altura da plântula e comprimento de suas folhas). Deste modo, variações fenotípicas nestes caracteres originam-se tanto por influência genotípica quanto ambiental, na população estudada (Stearns 1989, Scheiner 1993, Via et al. 1995).

A ocorrência de ecótipos em C. canjerana subsp. polytricha foi confirmada por diferenças significativas na altura das plantas e peso dos frutos e pela ocorrência de "trade-offs", apontados pelas normas de reação. Embora "trade-offs" não tenham sido confirmados pelo método quantitativo das correlações genéticas (i.e. as correlações não foram negativas e significativas), existe variação nas respostas plásticas entre ecótipos. Rausher (1988) afirma que basta a população apresentar pequena variabilidade para que mudanças evolutivas possam ocorrer por seleção disruptiva, não sendo para isto necessário que correlações genéticas negativas sejam significativas. Divergências nos resultados de análises quan- 
titativas já haviam sido reportadas por Pigliucci \& Schlichting (1996), que atribuiram tais limitações ao desconhecimento dos mecanismos genéticos específicos que atuam na promoção da plasticidade do caráter analisado.

Bradshaw (1963) constatou a formação de ecótipos na planta aquática Lemna, em uma distância inferior a 10 metros, mostrando que pequenas distân-
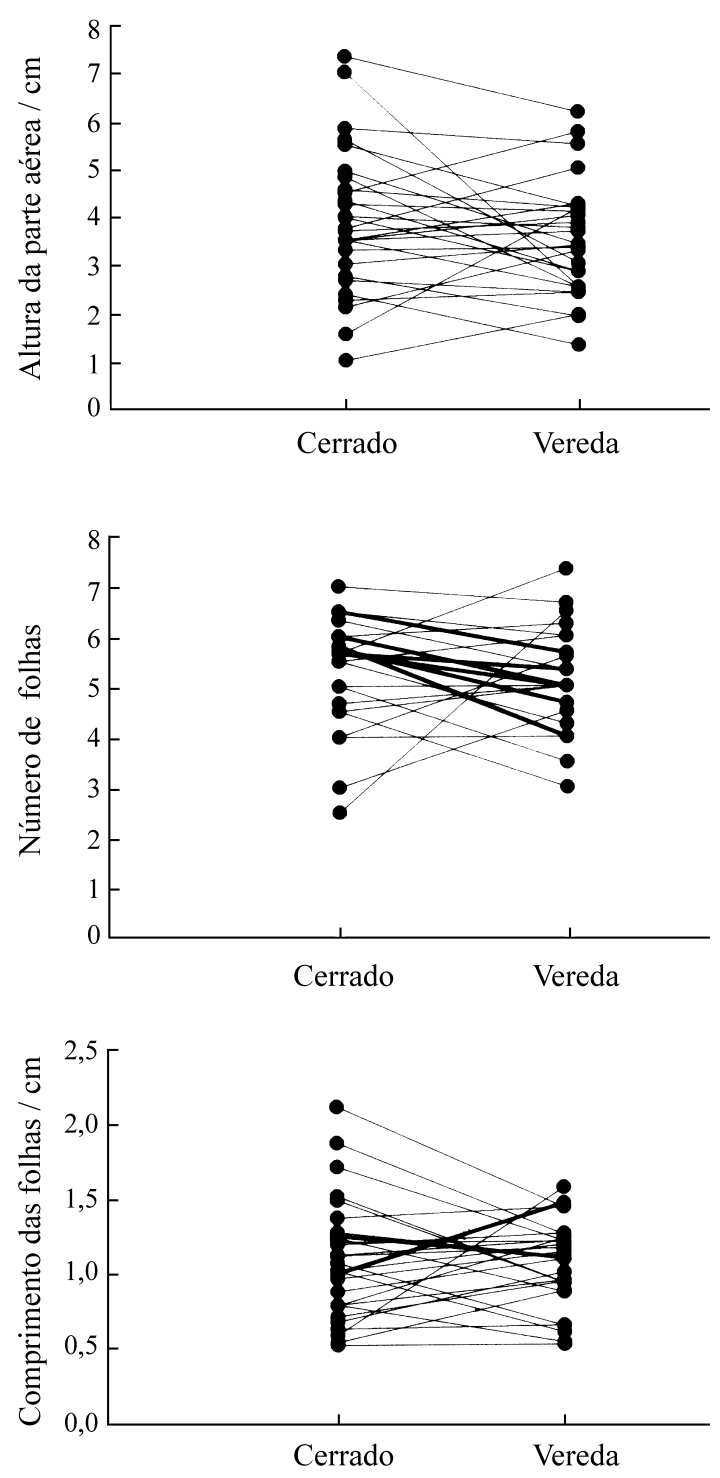

Figura 1. Normas de reação da altura da parte aérea, comprimento e número de folhas de plântulas de Cabralea canjerana subsp. polytricha cultivadas em solos de cerrado e vereda (censo 2 ). cias não constituem barreiras para que mudanças evolutivas rumo à adaptação e posterior formação de ecótipos aconteçam. Park et al. (1990) também verificaram formação de ecótipos em Cymbidium goeringii Reichb. na Coréia, induzida por fatores ecológicos locais. Hart \& Colvillec (1988) observaram a ocorrência de ecótipos de Trifolium repens L. altamente adaptados às diferentes concentrações de

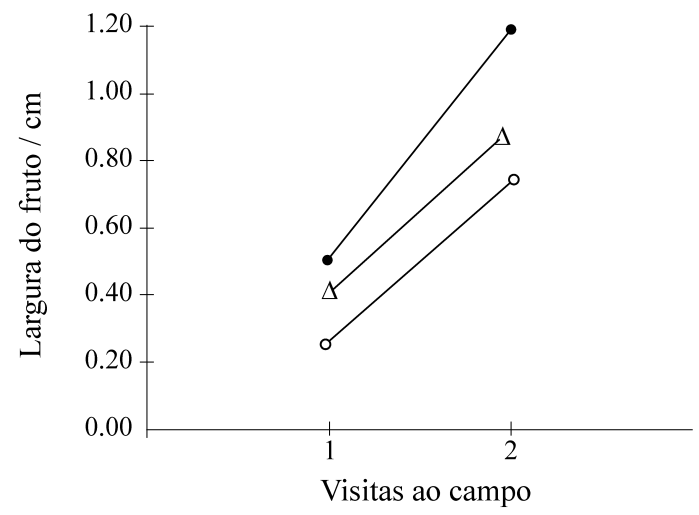

Figura 2. Medidas da largura (média) de frutos resultantes de cruzamentos em Cabralea canjerana subsp. polytricha na Reserva Ecológica do Clube Caça e Pesca Itororó de Uberlândia, MG, tomadas durante duas visitas ao campo (30 e 60 dias após cruzamentos $)(\bullet$ cerrado vs. cerrado; $\Delta$ cerrado vs. vereda; o vereda vs. vereda).

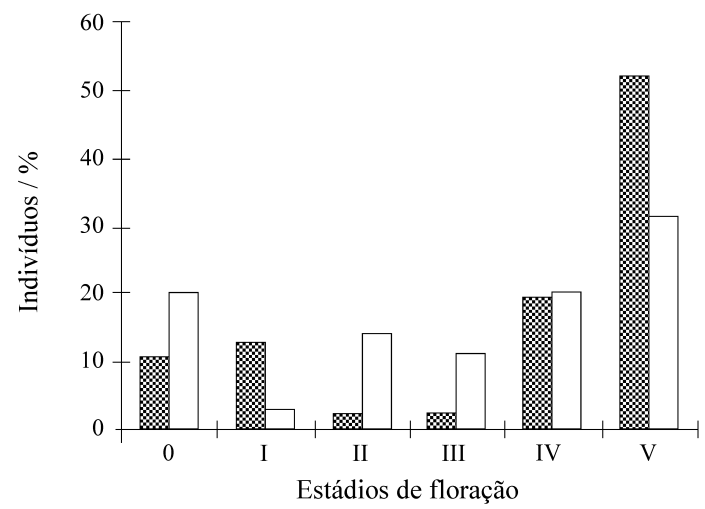

Figura 3. Estádios de floração de indivíduos estaminados e pistilados de Cabralea canjerana subsp. polytricha da Reserva Ecológica do Clube Caça e Pesca Itororó de Uberlândia, em áreas de cerrado e vereda ( 0 - ausência de botões; I - botões totalmente imaturos de cor verde; II - botões imaturos mas com a extremidade superior amarelada; III - botões amarelo-esverdeados; IV - botões de cor creme em pré-antese; V - flores abertas) ( $\square$ cerrado; $\square$ vereda). 
fósforo no solo e Helgadottir \& Snaydon (1986) verificaram ecótipos em Poa pratensis L. e Agrostis capillaris L., levando em consideração diversos fatores climáticos e edáficos.

As densidades de ocorrência da subspécie nas áreas de cerrado e vereda diferiram drasticamente. Um menor número de indivíduos ocorrendo em área de vereda parece indicar maiores gastos energéticos para sobrevivência e/ou crescimento e reprodução nesta área específica. Sendo assim, os maiores custos para a adaptação destes indivíduos em áreas de vereda podem ter relações com o menor porte dos adultos e menor peso dos frutos. Diferenças no peso dos frutos parecem ser atribuídas à espessura do pericarpo carnoso dos mesmos, visto que, os frutos não diferiram entre as áreas quanto ao número e peso de sementes viáveis.

A manutenção ou aumento de divergências morfológicas entre ecótipos pode ser favorecida pela assincronia no processo de floração entre as áreas (Prentice 1984, Prentice et al. 1995), o que dificultaria o cruzamento entre indivíduos de cerrado e de vereda em condições naturais.

A dinâmica de dispersão de sementes da subspécie também pode ter papel importante na formação e manutenção de ecótipos, que seriam favorecidos por sementes dispersas dentro da área de origem. $C$. canjerana subsp. polytricha é ornitocórica e um dos dispersores de suas sementes na área do cerrado estudada é Elaenia flavogaster (Tyrannidae), popularmente conhecida como "Maria-tola", "Mariaacorda" e "Maria-já-é-dia". Embora sendo um dispersor de grande vagilidade, podendo facilmente intercambiar sementes entre as áreas, há, segundo Pizo (1997), maior probabilidade de sementes serem descartadas sob o dossel da planta mãe, visto que o tamanho médio das sementes é favorável à rápida passagem no trato digestivo das aves. A ação de formigas e aves, como Ramphastos toco, também pode contribuir para a formação de ecótipos na área estudada. $R$. toco derruba, nas proximidades da planta mãe, vários frutos abertos e semi abertos, cujas sementes germinam com sucesso de cerca de $83 \%$. Além disto, formigas de diversas espécies removem o arilo destas sementes, após o que, segundo Pizo \& Oliveira (1998), são transportadas para micro-sítios potencialmente seguros, relativamente próximos.
A caracterização de grande variabilidade genotípica e considerável potencial plástico em $C$. canjerana subsp. polytricha entre indivíduos relativamente próximos traz importantes implicações na determinação de áreas de preservação, conservação e manejo da flora silvestre (Black et al. 1995). Perda de parte da variabilidade genética de uma população pode ocorrer, caso áreas delimitadas sejam inferiores ao mínimo necessário para a manutenção de ecótipos, aparentemente não detectáveis fenotipicamente (Prentice et al. 1995). Se divergências entre ecótipos forem gradativamente acentuadas e mantidas por seleção disruptiva, uma nova variedade ou subspécie de Cabralea canjerana poderá surgir em áreas de vereda, desde que a heterogeneidade ambiental desta área de transição seja mantida e que custos para a plasticidade aumentem com o grau de especialização (Lortie \& Aarssen 1996).

Agradecimentos - A Jimi Naoki Nakajima, Paulo Eugênio A.M. Oliveira e Warwick Estevam Kerr, pela leitura crítica do manuscrito e a David George Francis pela revisão do abstract.

\section{Referências bibliográficas}

BARROSO, G.M. 1984. Sistemática de Angiospermas do Brasil v.2. Imprensa Universitária da UFV, Viçosa.

BARREIROS, H.D.S. \& SOUZA, D.S.E. 1986. Notas geográficas e taxonômicas sobre Cabralea canjerana (Vell.) Mart., no Brasil (Meliaceae). Revista Brasileira de Biologia 46:1726.

BLACK, S. \& ANDERSON, S. 1997. Reaction norm variation between and within populations of two rare plant species, Vicia pisiformis and V. dumetorum (Fabaceae). Heredity 79:268-276.

BLACK, S., ERICSSON, G., GUSTAFSSON. L. \& LUNDKVIST, K. 1995. Ecological genetics of the rare species Vicia pisiformis: quantitative genetic variation and temperature response in biomass and fecundity. Acta Oecologica 16:261-275.

BRADSHAW, A.D. 1963. The analysis of evolutionary process involved in the divergence of plant population. Proceedings of the International Congress of Genetics 1:143.

BRADSHAW, A.D. 1965. Evolutionary significance of phenotypic plasticity in plants. In Advances in genetics (E.M. Caspary \& J.M. Thoday, eds.). Academic Press, New York. p.115-155.

DUDLEY, S.A. \& SCHMITT, J. 1996. Testing adaptive plasticity hypothesis: density-dependent selection on manipulated stem length in Impatiens capensis. American Naturalist 147:445-465.

FALCONER, D.S. 1989. Introduction to quantitative genetics. Hongman Sei \& Tech, New York. 
HART, A.L. \& COLVILLEC, C. 1988. Differences among attributes of white clover genotypes at various levels of phosphorus supply. Journal of Plant Nutrition 11:189-208.

HELGADOTTIR, A. \& SNAYDON, R.W. 1986. Patterns of genetic variation among populations of Poa pratensis and Agrostis capillaris from Britain (UK) and Iceland. Journal of Applied Ecology 23:03-719.

LORTIE, C.J. \& AARSSEN, L.W. 1996. The specialization hypothesis for phenotypic plasticity in plants. International Journal of Plant Science 157:484-487.

MACKENZIE, A. \& GULDEMOND, J.A. 1994. Sympatric speciation in aphids. II. Host race formation in the face of gene flow. In Individuals, populations and patterns in Ecology (S.R. Leather, A.D. Wait, N.I. Mills \& K.F.A. Walters, eds.). Intercept Ltda, Andover, p.379-196.

MAYR, E. 1982. Speciation and macroevolution. Evolution 36:1119-1132.

NIMER, E. \& BRANDÃO, A.M.P.M. 1989. Balanço hídrico e clima da região dos cerrados. IBGE, Rio de Janeiro.

PARK, J.S., CHUNG, J.D. \& CHUNG, M.S. 1990. Regional variation of banding patterns in some isozymes of Cymbidium goeringii in Korea. Journal of the Korean Society for Horticultural Science 31:176-183.

PENNINGTON, T.D., STYLES, B.D. \& TAYLOR, D.A.H. 1981. Meliaceae. Flora Neotropica Monograph 28:235-244.

PIGLIUCCI, M. \& SCHLICHTING, C.P. 1996. Reaction norms of Arabidopsis. IV. Relationship between plasticity and fitness. Heredity 76:427-436.

PIGLIUCCI, T.D., DIIORIO, P. \& SCHLICHTING, C.D. 1997. Phenotypic plasticity of growth trajectories in two species of Lobelia in response to nutrient availability. Journal of Ecology 85:265-276.

PIZO, M.A. 1997. Seed dispersal and predation in two populations of Cabralea canjerana (Meliaceae) in the Atlantic forest of Southeast Brazil. Journal of Tropical Ecology 13:559-578.

PIZO, M.A. \& OLIVEIRA, P.S. 1998. Interaction between ants and seeds of a nonmyrmecochorous neotropical tree, Cabralea canjerana (Meliaceae) in the Atlantic forest of Southeast Brazil. American Journal of Botany 85:669-674.
PRENTICE, H.C. 1984. Enzyme polymorphism, morphometric variation and population structure in a restricted endemic Silene diclinis (Caryophyllaceae). Biological Journal of the Linnean Society 22:125-144.

PRENTICE, H.C., LONN, M., LEFKOVITCH, L.P. \& RUNYEON, H. 1995. Associations between allele frequencies in Festuca ovina and habitat variation in the alvar grasslands on the Baltic Island of Oland. Journal of Ecology 83:391-402.

RAUSHER, M.D. 1988. Is coevolution dead? Ecology 69:898901.

RIZZINI, C.T. 1977. A germinação de Cabralea polytricha Juss. em confronto com C. laevis C. DC. (Meliaceae). Leandra 6-7:23-33.

SCHEINER, S.M. 1993. Genetics and evolution of phenotypic plasticity. Annual Review of Ecology and Systematics 24:35-68.

STEARNS, S.C. 1989. The evolutionary significance of phenotypic plasticity. Bioscience 39:463-445.

SULTAN, S.E. 1987. Evolutionary implications of phenotypic plasticity in plants. Evolutionary Biology 21:127-178.

SULTAN, S.E. 1996. Phenotypic plasticity for offspring traits in Polygonum persicaria. Ecology 77:1791-1807.

THOMPSON, J.D. 1991. Phenotypic plasticity as a component of evolutionary change. Trends in Ecology \& Evolution 6:246249.

VIA, S. 1990. Ecological genetics and host adaptation in herbivorous insects: the experimental study of evolution in natural and agricultural systems. Annual Review of Entomology 35:421-446.

VIA, S. \& LANDE, R. 1985. Genotype-environment interactions and the evolution of phenotypic plasticity. Evolution 39:505-522.

VIA, S., GOMULKIEWICZ, R., DEJONG, G., SCHEINER, S.M., SCHLICHTING, C.D. \& VANTIENDEREN, P.H. 1995. Adaptive phenotypic plasticity: consensus and controversy. Trends in Ecology \& Evolution 19:212-217.

ZAR, J.H. 1982. Biostatistical analysis. Pratice Hall, Inc., New Jersey. 